RESENHA

\title{
RESENHA DE TRADUÇÃO DA OBRA COMPÊNDIO DE PSICANÁLISE E OUTROS ESCRITOS INACABADOS
}

\section{Elisângela Dagostini}

Universidade Federal de Santa Catarina (UFSC), Brasil

elisangeladagostini@gmail.com

Willian Henrique Cândido Moura

Universidade Federal de Santa Catarina (UFSC), Brasil

willianhenry_@hotmail.com

DOI: https://doi.org/10.26512/caleidoscopio.v4i1.29077

Recebido em: 07/01/2020

Aceito em: 26/06/2020

Publicado em dezembro de 2020

FREUD, Sigmund. Compêndio de Psicanálise e outros escritos inacabados. Tradução de Pedro Heliodoro Tavares. Belo Horizonte: Autêntica, 2014. (Obras Incompletas de Sigmund Freud). Edição Bilíngue. 251p.

Sigmund Freud nasceu em 1856, na cidade de Freiberg (atual Př́́bor), na região da Morávia. De origem judaica, Freud foi um médico neurologista, criador da Psicanálise. Por meio da técnica da hipnose, iniciou seus estudos no tratamento de pacientes diagnosticadas com histeria, o que obteve tamanha influência em seus estudos e pesquisas posteriores, relacionados à mente, ao consciente e ao inconsciente. Até os dias atuais, suas teorias psicanalíticas são utilizadas por seus seguidores no mundo todo. Faleceu em Londres, em 1939, aos 83 anos, em decorrência de um câncer no palato.

O presente trabalho objetiva realizar uma resenha da tradução do livro Compêndio de Psicanálise e outros escritos inacabados de Sigmund Freud. Esta obra foi publicada pela Editora Autêntica, em 2014, e apresentada em edição bilíngue Alemão/Português pelo psicanalista, germanista, tradutor e professor de alemão, Pedro Heliodoro Tavares. Em sua carreira acadêmica, o tradutor realizou doutorado em Psicanálise e Psicopatologia pela Université Paris VII e pós-doutorado em Estudos da Tradução pela Universidade Federal de Santa Catarina. Atualmente é 
professor da Universidade Federal de Santa Catarina, atuando na graduação em Letras: Alemão e na Pós Graduação em Estudos da Tradução.

Além de traduzir, Pedro Heliodoro Tavares se dedica à pesquisa da Psicanálise e suas interfaces com as Letras e com a Tradução. Assina obras como Freud \& Schnitzler - Sonho Sujeito ao Olhar (2007); Fausto e a Psicanálise - Sopros de Sinthome na Forja do Pactário (2012); Versões de Freud - breve panorama crítico das traduções de sua obra (2011); Tradução e Psicanálise (2013) e Psicanálise entre línguas (2016).

Dentre as várias traduções das obras de Freud no Brasil, contava-se apenas com versões indiretas, feitas a partir do inglês e do francês pela Editora Imago que detinha os direitos autorais até o ano de 2009. A partir dessa data, o tradutor apresenta que as obras de Freud entraram para o domínio público e dessa forma foi possível ter acesso às traduções diretas dos textos-fontes em alemão. Muitos estudiosos brasileiros, principalmente pesquisadores de Psicanálise, pediam insistentemente para que a fluência e a criatividade de Freud fossem respeitadas nas edições brasileiras e que houvesse o cuidado acerca "de um 'vocabulário brasileiro' relativo à metapsicologia freudiana". (2014, p. 242).

Desta forma, elencamos que na obra Versões de Freud (2011), Pedro Heliodoro Tavares faz um verdadeiro apanhado das obras e versões traduzidas publicadas em diversas línguas, e, por meio de tabelas, compara os termos traduzidos do alemão para outros idiomas. No excerto a seguir, extraído de Tavares (2011), demonstramos apenas a comparação de um termo apresentado pelo autor, trieb, no qual analisa o texto original de Freud e as traduções entre duas editoras inglesas e uma espanhola:

\section{Tabela 1: Tradução do termo trieb, na Standard Edition (Inglaterra), Biblioteca Nueva (Espanha) e Penguin Books (Inglaterra).}

\begin{tabular}{|c|c|c|c|}
\hline $\begin{array}{c}\text { Freud (original) } \\
\text { Gesammelte Werke/ } \\
\text { Studienausgabe } \\
\text { (Alemanha) }\end{array}$ & $\begin{array}{c}\text { James Strachey } \\
\text { Standard Edition } \\
\text { (Inglaterra) }\end{array}$ & $\begin{array}{c}\text { Luis Ballesteros } \\
\text { Obras Completas - } \\
\text { Biblioteca Nueva } \\
\text { (Espanha) }\end{array}$ & $\begin{array}{c}\text { Adam Phillips } \\
\text { Penguin Books } \\
\text { (Inglaterra) }\end{array}$ \\
\hline Trieb & Instinct & Instinto & Drive \\
\hline
\end{tabular}

Fonte: Retirado de Tavares (2011, p. 71).

Percebe-se o esforço de Tavares (2011) em demonstrar os diferentes resultados das traduções feitas a partir do alemão como língua de partida, para o 
inglês, com dois tradutores diferentes, que apresentaram duas traduções diferentes para a mesma palavra, assim como para a tradução na língua espanhola, constatando problemas terminológicos.

Do mesmo modo, Tavares (2011) apresenta a comparação para as novas edições traduzidas para a língua portuguesa brasileira, diretamente do alemão:

Tabela 2: Tradução do termo trieb nas novas traduções brasileiras feitas diretamente do alemão

\begin{tabular}{|c|c|c|c|}
\hline $\begin{array}{c}\text { Freud (original) } \\
\text { Gesammelte Werke/ } \\
\begin{array}{c}\text { Studienausgabe } \\
\text { (Alemanha) }\end{array}\end{array}$ & $\begin{array}{c}\text { Luiz Alberto Hanns } \\
\text { Editora Imago - RJ }\end{array}$ & $\begin{array}{c}\text { Paulo César de Souza } \\
\text { Editora Companhia das } \\
\text { Letras - SP }\end{array}$ & $\begin{array}{c}\text { Renato Zwick } \\
\text { Editora L\&PM - RS }\end{array}$ \\
\hline Trieb & Pulsão & Instinto & Impulso \\
\hline \multicolumn{2}{|c|}{ Fonte: Retirado de Tavares (2011, p. 127-128). }
\end{tabular}

Assim como nas edições inglesas, as novas edições brasileiras ainda apresentam questões que divergem terminologicamente entre si. Destarte, Tavares (2011) discute que não é possível afirmar qual é a melhor ou a pior versão traduzida, contudo, o autor salienta que é possível indicar para qual tipo de leitor uma ou outra edição brasileira é mais adequada, tendo em vista as questões estilísticas e terminológicas, bem como a formação e as influências dos tradutores por detrás de cada uma delas.

Com isso, buscamos apresentar algumas das divergências terminológicas existentes nas traduções das obras de Freud, antes e depois dos escritos do autor terem adentrado ao domínio público, o que resultou na tradução da obra por nós resenhada. Deste modo, enfatizamos que esta tradução do Compêndio de Psicanálise e outros escritos inacabados foi realizada mediante pesquisas de um tradutor, germanista, psicanalista e pesquisador das traduções das obras de Freud.

Destarte, é importante ressalvar que na tradução do Compêndio de Psicanálise e outros escritos inacabados, obra integrante da coleção Obras Incompletas de Sigmund Freud, percebe-se o uso de diversos paratextos no decorrer da edição, o que indica certo conhecimento, por parte do tradutor, da necessidade de notas explicativas e justificativas das escolhas tradutórias realizadas ao longo da obra. Ressalta-se que as traduções da coleção foram 
realizadas diretamente de sua língua original, o alemão, e que houve o envolvimento de uma equipe multidisciplinar de tradutores e consultores de diversas áreas, como a Psicanálise, Letras e Filosofia, os quais procuraram não apenas traduzir direto do alemão, mas também atentar para os usos dos conceitos da comunidade psicanalítica brasileira. Além disso, os editores descrevem que os textos que compõem a coleção foram traduzidos de forma temática e com os paratextos e notas organizados conforme as exigências de cada caso, descrevendo com ética os textos e exemplos pautados na clínica.

Partindo então para uma análise paratextual da obra, já na capa do volume encontramos na parte superior o título da coleção, em caixa alta, OBRAS INCOMPLETAS DE SIGMUND FREUD, com o nome Sigmund Freud grafado em negrito, sendo transposto pela digitalização da assinatura de Freud em tamanho maior, dando ênfase ao nome do autor. Logo abaixo, há o título da obra COMPÊNDIO DE PSICANÁLISE e outros escritos inacabados, sendo complementado pela indicação da edição bilíngue, o que já indica uma diferença entre esta e as outras versões traduzidas não bilíngues.

Outro fator de destaque na capa é a autoria da tradução, creditada a Pedro Heliodoro Tavares, como já mencionado anteriormente. Essa informação permite aos estudiosos da psicanálise e possíveis leitores do livro identificarem de imediato, ao visualizarem a capa da obra, quem é o tradutor, fato que pode ser somado à biografia do mesmo, na página 251, pois está exposto que se trata de um tradutor que é psicanalista, germanista e também pesquisador das traduções de Freud. Frisamos, como pesquisadores da área dos Estudos da Tradução, a importância de se valorizar o trabalho e a voz do tradutor, creditando a autoria ao mesmo, que muitas vezes não é reconhecida.

Nas orelhas desta edição, encontramos uma breve explanação da obra e da coleção à qual faz parte. Destacamos o fato mencionado na primeira orelha, que este livro "reúne a terminologia freudiana em sua versão mais bem-acabada, em uma edição bilíngue e extensivamente anotada." (grifo nosso). Reiterando-se assim a relevância desta obra para a Psicanálise e o esforço em disponibilizar lado a lado obra original e obra traduzida, somando-se ao cuidado com os termos utilizados relativos à psicanálise clínica, e também com as informações contidas nas notas do tradutor, posfácio e nas notas dos editores das Obras Incompletas de Sigmund Freud. 
Percebe-se, nesta edição, a preocupação em ressaltar o original em alemão. Antes do prefácio, a obra apresenta a digitalização da primeira página do manuscrito do Compêndio de Psicanálise, e ainda traz que o texto original, utilizado para a tradução, partiu da edição de 1999 da Editora Fischer, de Frankfurt, enfatizando que a primeira edição em alemão foi publicada em 1940.

No prefácio da obra, Freud descreve que pretende reunir as teses de Psicanálise da forma mais concisa e resoluta, sem intenção de exigir crença ou despertar convicções. No prefácio também se iniciam as indicações numéricas para as notas do tradutor que se encontram após a tradução.

Na primeira parte, A natureza do psíquico, introduzida pelo Capítulo 1, 0 aparelho psíquico, Freud apresenta que a psicanálise parte de um pressuposto básico em que a discussão é reservada ao pensamento filosófico e sua justificativa encontra-se nos resultados. 0 autor descreve sobre o aparelho psíquico, levando em consideração as principais características do Eu e a percepção sensorial entre o mundo interno e o externo, sendo que o Eu procura a satisfação, o prazer. Quando este prazer diminui, o desprazer manifesta-se como angústia, advinda do exterior ou do interior. Na infância, o ser humano em formação depende de seus pais, e desta forma tem-se o Supereu. A ação do Eu é considerada correta quando supre as exigências do Isso, do Supereu e da realidade. Influencia a criança às tradições da família, à raça e ao povo e ao meio social em que está inserida. Desta forma, considera-se que mesmo Freud tendo explicado e descrito sobre conceitos principais de Psicanálise, estes foram apenas passos iniciais no estudo, segundo o próprio Freud. Ademais, neste capítulo, tem-se a primeira nota de rodapé escrita por Freud, que apresenta o Isso como sendo a parte mais antiga do aparelho psíquico, e que "[...] permanece sendo a mais importante por toda a vida. A partir dela também se iniciou o trabalho de investigação da Psicanálise”. (p. 17).

Seguindo, no capítulo 2, Doutrina das pulsões, Freud fala sobre o Eu, o Isso e o Supereu, destacando que as pulsões são forças que existem por trás das tensões motivadas pela necessidade do Isso. 0 autor destaca que existem duas pulsões essenciais: Eros (ou pulsão do amor) e a pulsão da destruição. 0 objetivo de Eros "é o de sempre produzir maiores unidades e assim mantê-las, quer dizer, a ligação." (p. 25). Por sua vez, em oposição a Eros, o objetivo da pulsão da destruição "é o da dissolução das conexões e assim o de destruir as coisas." (p. 25). 
No capítulo 3, O desenvolvimento da função sexual, Freud aduz sobre o desenvolvimento sexual, revelando que a vida sexual do ser humano não começa só na puberdade, mas logo após o nascimento, aprofundando também sobre as diferenças entre o entendimento sobre o sexual (mais amplo) e o genital (mais específico). Ainda que a vida sexual abranja a função da obtenção do prazer do corpo e que estas estão a serviço da reprodução, essas três fases (sexual, prazer e reprodução) se sucedem e demonstram importantes descobertas com relação ao corpo e aos distúrbios de desenvolvimento nos primórdios da vida do ser humano.

Por sua vez, o Capítulo 4, Qualidades psíquicas, descreve sobre o constructo do aparelho psíquico, suas energias e como estas se organizam numa função fisiológica. Freud fala sobre os processos psíquicos, que podem ser: conscientes, préconscientes ou inconscientes e como eles acontecem, transformando-se para enfim proteger o aparelho psíquico.

Encerrando a primeira parte, em Explicação pela interpretação do sonho, Freud explica o conteúdo manifesto e o conteúdo latente do sonho, em que duas espécies dão formação ao sonho: ou um desejo inconsciente, ou um anseio residual da vida desperta, trabalhando ou o Isso, ou o Eu. Através dos mecanismos inconscientes do sonho é possível esclarecer a formação dos sonhos, sendo que o entendimento dos sintomas e das formações enigmáticas podem gerar neuroses e psicoses a serem estudadas.

Dando sequência no livro, chegamos à Parte II, A tarefa prática. Em seu capítulo introdutório, A técnica psicanalítica, Freud argumenta que o sonho é uma psicose inofensiva e de curta duração. Supondo que "o Eu tem a tarefa de suprir as exigências de suas três formas de dependência, a saber: da realidade, do Isso e do Supereu, e, ao mesmo tempo, a de manter sua própria organização, preservar sua autonomia." (p. 85). 0 psicanalista descreve sobre a transferência quando o paciente está em sessão de análise, sobre a resistência e também a inércia da libido.

É apresentado no Capítulo 7, Uma amostra do trabalho psicanalítico, o funcionamento do aparelho psíquico, onde encontram-se as neuroses e as psicoses. Nesta parte, foram aprofundados os estudos sobre as neuroses, pois parecem acessíveis aos métodos psicológicos. Entre os condicionantes da neurose, encontram-se a influência cultural e o fator pulsional específico, além de que, é possível dizer que os sintomas das neuroses são invariavelmente uma satisfação que 
substitui o anseio sexual, também o estudo sobre os recalques, a biologia e a sexualidade de meninos e meninas.

Adentrando à Parte III, O ganho teórico, o Capítulo 8, 0 aparelho psíquico e o mundo exterior, discorre sobre algumas conclusões prévias em que o Isso é voltado, unicamente, à obtenção do prazer, o Eu à tarefa da autopreservação e ainda a conclusão de que é preciso aprofundar os estudos do Eu em relação ao mundo exterior real, ou à rechação pulsional vinda do mundo interior.

Finalizando, no Capítulo 9, 0 mundo interior, Freud analisa o papel do Supereu, do Eu, e do Isso, revelando a importância e a interferência de cada um deles desde a infância. "A noção de um Eu que faz mediação entre o Isso e o mundo exterior, que assume as defesas contra as exigências excessivamente extensas de ambas as partes." (p. 173). Dessa forma, "uma parte do mundo exterior é, ao menos parcialmente, abandonada como objeto e acolhida no Eu" (p. 173), integrando-se ao mundo interior. "Chamamos tal instância de Supereu e a sentimos em suas funções julgadoras como nossa consciência moral." (p. 175).

Concluída esta etapa da edição, seguem-se as notas do tradutor. São 17 páginas de cor cinza dedicadas a 152 notas em que Pedro Heliodoro Tavares esclarece algumas de suas escolhas tradutórias, além de apresentar explicações acerca dos termos-chaves do vocabulário freudiano em língua alemã, com traduções e análises dos termos em alemão, adequando-os ao português. Fica claro, portanto que esta edição eleva a visibilidade do tradutor, valorizando o trabalho deste profissional, além de apresentar informações que, se não fossem trazidas sob a forma de notas do tradutor, posfácio e notas do editor, ficariam esquecidas ou inexplicáveis.

Após as notas do tradutor seguem-se Outros escritos inacabados, traduzidos em língua portuguesa, não acompanhados do original em língua alemã. Há ao final de cada escrito inacabado, notas do tradutor explicando escolhas e aspectos referentes à inconclusão desses textos. A começar pela Cisão do eu no processo de defesa, em que Freud aborda que a criança busca respostas para a pulsão e a reclamação da realidade com reações opostas. Desta forma, Freud deixa inacabada sua conclusão, descrevendo apenas comparações em relação à mitologia grega.

Em Fragmentos do espólio, texto composto por uma tradução de uma página e meia sem o acompanhamento do original em alemão, é explicado nas notas do 
tradutor que o fragmento se trata de anotações isoladas de Freud, em forma de esquemas e enigmas.

Seguindo, em Some elementar lessons in psycho-analysis [Algumas lições elementares sobre psicanálise], Freud esclarece a razão e a importância da Psicanálise como ciência e como área do saber. Na primeira nota do tradutor, Tavares esclarece o uso da língua inglesa nomeando este escrito inacabado. "Ainda que o texto tenha sido redigido em alemão, Freud o intitula em língua inglesa. Como foi escrito no exílio londrino, parece provável que seu autor tivesse o intuito de publicá-lo inicialmente na língua local." (p. 218).

Após os Outros escritos inacabados, encontramos o Posfácio, intitulado $O$ testamento inacabado de Sigmund Freud, assinado pelos editores da Coleção Obras Incompletas de Sigmund Freud, Pedro Heliodoro Tavares e Gilson Iannini. Os editores apresentam uma biografia do final da vida de Freud, além de indicarem os locais e anos de maiores produções de obras relativas à Psicanálise. Ainda, abordam que o "Compêndio de Psicanálise é certamente um texto-testamento. Um importantíssimo documento acerca do legado e da teoria da prática da Psicanálise." (p. 227).

A obra de Freud é cheia de divergências no que se refere as suas traduções, como pode ser vislumbrado em Versões de Freud, Tavares (2011). Dessa forma, o fato das obras de Freud terem entrado para o domínio público fez com que surgisse a possibilidade de novas traduções para a língua portuguesa, como no caso da tradução realizada por Pedro Heliodoro Tavares, na coleção bilíngue Obras Incompletas de Sigmund Freud. Traduções como essa demonstram a relevância do papel e da profissão de tradutor, que, neste caso, por meio das notas do tradutor, oferecem esclarecimentos que até então haviam sido ignorados ou determinados sem justificativa em versões publicadas anteriormente.

\section{REFERÊNCIAS}

COSTA, Walter Carlos; TAVARES, Pedro Heliodoro; ROSSI, Emiliano de Brito (Orgs.). Psicanálise entre línguas. Rio de Janeiro: 7 Letras, 2016.

TAVARES, Pedro Heliodoro. Freud \& Schnitzler: Sonho sujeito ao olhar. São Paulo: Annablume, 2007. 
TAVARES, Pedro Heliodoro. Versões de Freud: breve panorama crítico das traduções de sua obra. Rio de Janeiro: 7 Letras, 2011.

TAVARES, Pedro Heliodoro. Fausto e a Psicanálise: Sopros de Sinthome na forja do pactário. São Paulo: Annablume, 2012.

TAVARES, Pedro Heliodoro; COSTA, Walter Carlos; PAULA, Marcelo Bueno de (Org.). Tradução e Psicanálise. Rio de Janeiro: 7 Letras, 2013.

\section{Biografia dos autores}

Elisângela Dagostini é doutoranda em Estudos da Tradução pela Pós-Graduação em Estudos da Tradução da Universidade Federal de Santa Catarina (PGET-UFSC). Especialista em Ciência e Tecnologia pela UFSC e MBA em Gestão de Pessoas pela Universidade do Norte do Paraná (UNOPAR). Graduada em Administração de Empresas pela Universidade Regional Integrada do Alto Uruguai e das Missões (URI). Membro do Grupo de Pesquisa Strategy as Practice (SAP). Tem interesse em pesquisas na área de Estratégia em Administração e em Estudos da Tradução. Atualmente é servidora técnica administrativa da Universidade Federal de Santa Catarina.

Willian Henrique Cândido Moura é doutorando e mestre em Estudos da Tradução pela Pós-Graduação em Estudos da Tradução da Universidade Federal de Santa Catarina (PGET-UFSC). Especialista em Tradução Audiovisual de Espanhol pela Universidade Estácio de Sá e graduado em Letras: Português e Espanhol pela Universidade Federal da Fronteira Sul (UFFS). Membro do Grupo de Estudos e de Pesquisas em Tradução e Tecnologia (GETRADTEC). Tem interesse em pesquisas sobre os Estudos da Tradução Audiovisual, dublagem, legendagem, fansubbing e tabus linguísticos. É bolsista CAPES. 